\title{
Passive snow removal with a vortex generator at the Pegasus runway, Antarctica
}

\author{
R. M. Lang, ${ }^{1}$ George L. Blaisdell ${ }^{2}$ \\ ${ }^{1}$ Sigma Technologies Inc., 6970 Ford Dr. N.W., Gig Harbor, WA 98335, U.S.A. \\ ${ }^{2}$ Cold Regions Research and Engineering Laboratory, U.S. Army Corps of Engineers, 72 Lyme Road, Hanover, NH 03755-1290, U.S.A.
}

\begin{abstract}
During the construction phase of the Pegasus runway on the McMurdo Ice Shelf, relatively large amounts of snow and ice were cleared to meet basic grade requirements for the runway surface. A considerable amount of material remains adjacent to the runway in two north-south extending mounds (berms). The runway was originally constructed on an experimental basis so attention was not focused on developing and executing a snow-removal/accumulation plan. After the runway was successfully constructed and supporting routine flight operations, concern developed over the possibility of snow accumulation adjacent to the berm area eventually inundating the runway. The intent of this project was to analyze snow accumulation and to recommend passive methods for removing some of the berm material and snow adjacent to the berm. We found that large quantities of excess snow could be removed by use of vortex fences which cause erosion on the leeward side of the fence. The vortex fence was designed to be portable (unlike traditional jet or blower fences) and self-orienting into the wind to allow snow removal regardless of the wind direction. The vortices generated by the fence do not dissipate rapidly, providing effective and sustained erosion.
\end{abstract}

\section{INTRODUCTION}

The United States Antarctic Program (USAP) relies on aircraft operating between Christchurch, New Zealand, and McMurdo Station, Antarctica, to provide nearly all personnel support and a considerable amount of cargo transport to the continent. The first flights of the season land on a skiway at Williams Field in late-August using specialized LC-130 Hercules (ski-wheel). In October, the main contingent of personnel flies to McMurdo in wheeled C-130 Hercules, C-141 Starlifter and C-5 Galaxy aircraft operating off a runway of first-year sea ice. This runway is abandoned in midDecember due to strength deterioration.

Until the 1992-93 season, the USAP was limited solely to ski-equipped aircraft (LC-130 Hercules) for all of its needs from the time the sea-ice runway closed throughout the remainder of the season. To alleviate this bottleneck, the USAP began development of a runway suitable for conventional aircraft use during the latter part of the austral (Southern Hemisphere) summer. Engineering studies began in 1989 and culminated in 1993 in a wheeled runway on the Ross Ice Shelf near McMurdo, specifically for use during the period after the sea ice was no longer usable (Blaisdell and others, 1994). The runway, located at the Pegasus site, was demonstrated in 1993 using an LG-130 aircraft (operating on wheels) and by a conventional C-130 Hercules. During subsequent field seasons, the Pegasus runway has been used extensively for wheeled operations of LC-130 and C-130 planes, in addition to a successful C-141 flight test followed by many operational C-141 flights.

Since the Pegasus runway was developed as a feasibility study, attention was focused on the primary engineering of the runway (producing an even, level surface with a strength capable of supporting heavy wheeled aircraft) and little thought was given to long-term snow management. Many factors were important in selecting the position and orientation of the Pegasus runway. Since only one runway was planned, a single orientation was required. Given the existing wind patterns (Fig. 1), the runway alignment was selected to coincide with the direction of the strong or storm winds. The prevailing wind, generally low speed, is a

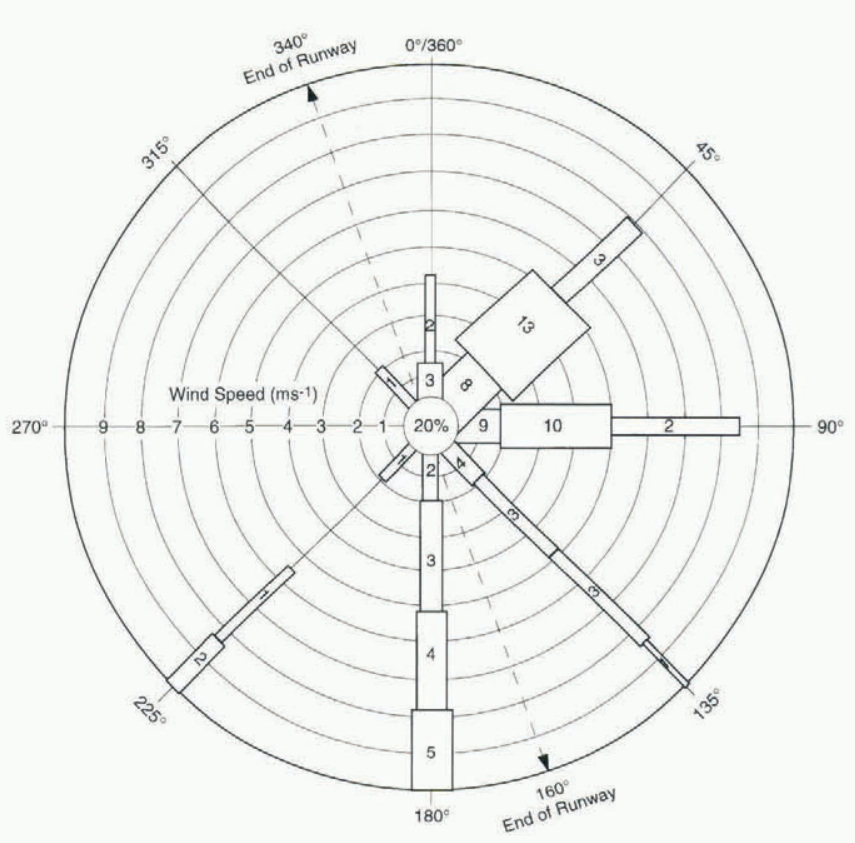

Fig. 1. Wind rose for the "Pegasus South" automated weather station (AWS) using monthly average data for the period 1 January 1993 to 31 December 1994. 
cross-wind with respect to the runway. This selection was based strictly on aircraft operational needs; the ramifications of snow drifting and accumulation were not considered. Also, the Pegasus site was selected because of the ideal glaciological conditions, within a transition between snow-accumulation and snow-ablation zones (Klokov and Diemand, 1995). It was feared that changing the natural balance of snow accumulation in the area, due to construction activities, would perhaps lead to unstable drift development, causing premature loss of the facility. There was also concern for the cost, difficulties and labor-intensive effort required to return the site to its original "steady-state" condition. An additional aspect of snow management at the site is the need to allow some snow accumulation in order to supply the required protective snow cover (between 15 November and 10 January) to prevent melting of the ice surface (Lang and Blaisdell, 1996).

The goal of this study was to determine whether an innovative passive snow-manipulation technique could be applied at the Pegasus site to (a) remove or reduce significantly the berms created during construction, and (b) to assist in managing or avoiding snowdrift problems in the future. Studies indicate that implementing passive snowcontrol treatments may cost up to 100 times less than active measures (Tabler, 1991). Passive snow-control measures are typically implemented to facilitate snow deposition in a preferential manner. In the case of the Pegasus site, our goal was to find a passive control device that would allow selective increase in snow scour, thereby encouraging snow movement out of the area of the runway. This paper describes a successful attempt at configuring a full-scale vortex generator to locally erode recently deposited snow and relocate this snow to the ablation zone west of the berm area or north from the runway.

\section{PASSIVE SNOW-REMOVAL EXPERIMENTS}

Snow-control devices have been studied for some time and have been successfully used in field applications for roads (Wang Zhonglong and Chen Yuan, 1980) and on and around buildings (Williams, 1989). Jet roofs (sometimes called blower fences) are commonly used for localized snow removal in alpine terrain (Montagne and others, 1968). However, the jet-roof design has minimal potential to be constructed to orient itself into the wind and thus avoid cross-wind deposition.

To the best of our knowledge, the only previous tests of vortex fences were small-scale similitude experiments conducted by Meroney and Meroney (1989). However, the positive results of these small-scale tests were encouraging. By design, a vortex fence produces longitudinally aligned vortices on the lee side of the fence. These vortices can endure for long distances before dissipating. This phenomenon, the production of vortices by a delta wing, can be physically observed during the landing of the space shuttle (seen in longitudinal axis dust swirls trailing the spacecraft wing tips). By creating locally increased air velocities over snow surfaces, snow movement can be produced. It is required that the threshold velocity be exceeded, enabling localized motion of surface particles due to the near-surface vortex velocities. When this occurs, snow is entrained in the vortex flow and snow is removed directly under the vortices.

The vortex fence can be easily adapted to accommodate

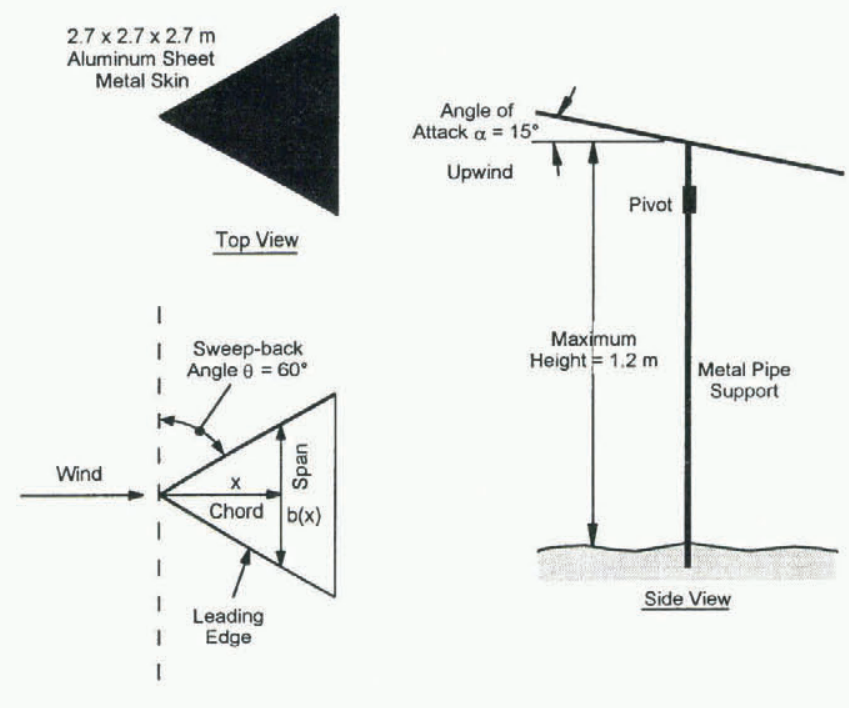

Fig. 2. Dimensions of the full-scale vortex fence.

a rotating head so that the natural pressure gradient surrounding the fence will cause it to self-orient. We constructed a full-scale vortex fence (Fig. 2), whose dimensions were based on our initial small-scale field-test results with fixed-orientation vortex generators, and on the scale-model test results of Meroney and Meroney (1989). The planform of the fence is the top view or largest surface of the wing. The chord $x$ of the wing is the distance from the apex of the leading edge toward the trailing edge; the span $b(x)$ is the dimension of the wing perpendicular to the chord (Fig. 2). The aspect ratio AR of the wing is defined by

$$
\mathrm{AR}=\frac{2 b(x)}{x}=\frac{4}{\tan \theta}
$$

where $\theta$ is the sweep-back angle, or the angle measured from the leading edge of the wing to a plane perpendicular to the wind velocity (McCormick, 1995) (Fig. 2). For our fence, $\theta$ was chosen to be $60^{\circ}$ for ease of construction, giving the wing an aspect ratio of 2.31 . Once a vortex is generated by a wing, it should tend to decay very gradually by both turbulent and viscous diffusion. Downstream, the cross-section of the vortex core increases, which in turn decreases the maximum tangential velocity $V_{\mathrm{t}}$. Vortex circulation $\Gamma$ along the vortex core is defined as the product of the vortex circumference and the tangential velocity $V_{\mathrm{t}}(r)$.

$$
\Gamma(r)=2 \pi r V_{\mathrm{t}}(r)
$$

where $r$ is the radial measure of the vortex, as shown in Figure 3 . The strength of the vortex is measured by the swirl angle $\zeta$ which is defined relative to the tangential velocity to the free-stream (wind) velocity $V$ as,

$$
\zeta=\tan ^{-1}\left(\frac{V_{\mathrm{t}}(r)}{V}\right) .
$$

If the vortex strength is too high, an instability known as vortex-bursting may occur. The critical factor for the design of this type of wing for snow removal is to define an optimal geometry where vortex bursting (break-down) occurs as far downstream from the wing as possible (McCormick and others, 1968; McCormick, 1995). This phenomenon is similar to the well-known "hydraulic jump" when channel flow transitions from supercritical to sub-critical, resulting in a considerable energy loss. Experimentally, it has been determined that, if the angle of attack $\alpha$ is increased in excess of approximately $22^{\circ}$, the leading-edge vortices become strong 


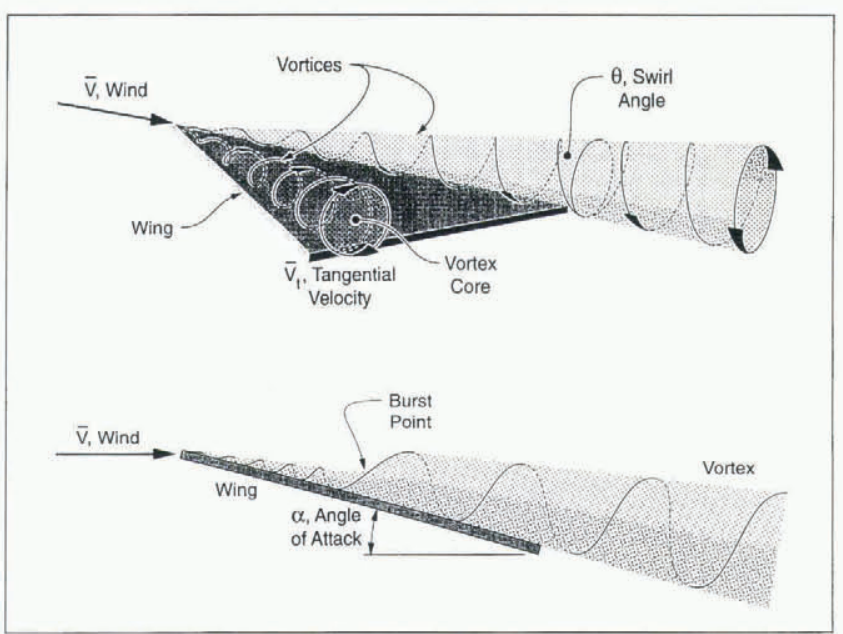

Fig. 3. Sketch of critical dimensions of vortex fence and vortex development.

enough to cause vortex-bursting over the wing itself (McCormick, 1995). (An illustration of this undesirable flow instability is depicted in the lower part of Figure 3.) However, there is an inordinate amount of scatter in the data, suggesting that the burst point is not a sharply defined location that can be calculated for known wing-shape parameters and wind velocity. Hence, no empirical relationship has been derived to approximate the burst point as a function of velocity and wing shape. By choosing $\alpha=15^{\circ}$ (i.e. less than the approximation of $22^{\circ}$ for bursting over the wing) for our specific application, this energy loss in the generated vortices appears to have been avoided.

The design of our fence also included a rotating head and, at the initiative of the fabricator, a fin on the lee side to assist in re-orientation. (The fin should not be necessary since the fence geometry will allow it to naturally orient into any wind direction.) The fence was constructed as a $2.7 \mathrm{~m}$

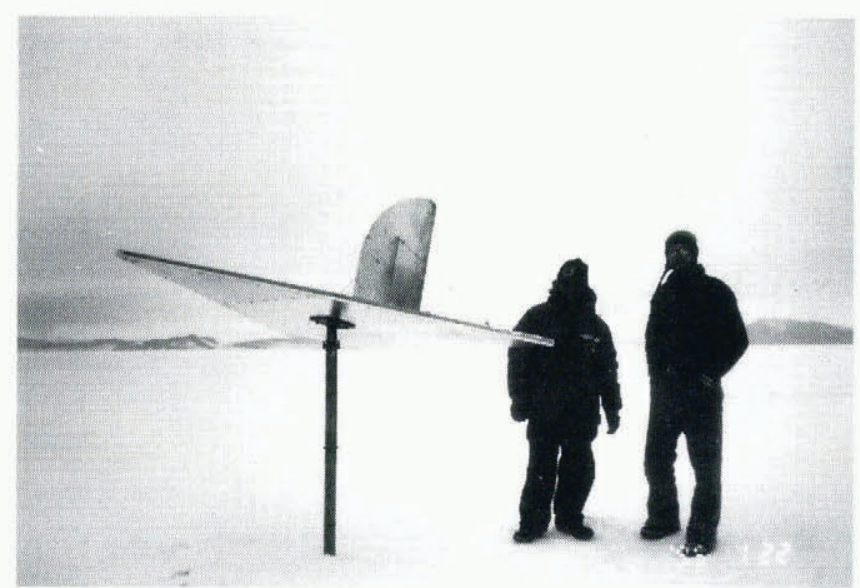

Fig. 4. Photograph of the installed vortex generator at Pegasus runway.

sided equilateral triangle (Fig. 2). Figure 4 is a photograph of the installed fence. Height above ground must also be a critical factor in vortex-fence performance; unfortunately, the small-scale tests of Meroney and Meroney (1989) did not indicate an optimum height. Based on our experience, we recommend a fence height of less than twice the planform height ( $2.34 \mathrm{~m}$ for our design) of the wing. Our fullscale vortex fence was installed at a height of approximately $1.2 \mathrm{~m}$ from the snow surface.

A survey-target area for monitoring snow-surface changes was established around the fence (Fig. 5). A profile of the runway surface, berm areas and vortex-fence target area is depicted in Figure 6. It was expected that erosion would occur to the leeward side relative to both the storm wind and the prevailing wind. It was not expected that snow volumes would be reduced in the windward areas of the fence (i.e. the fence could only affect snow loss on its leeward cone). The natural snow deposition-erosion pattern

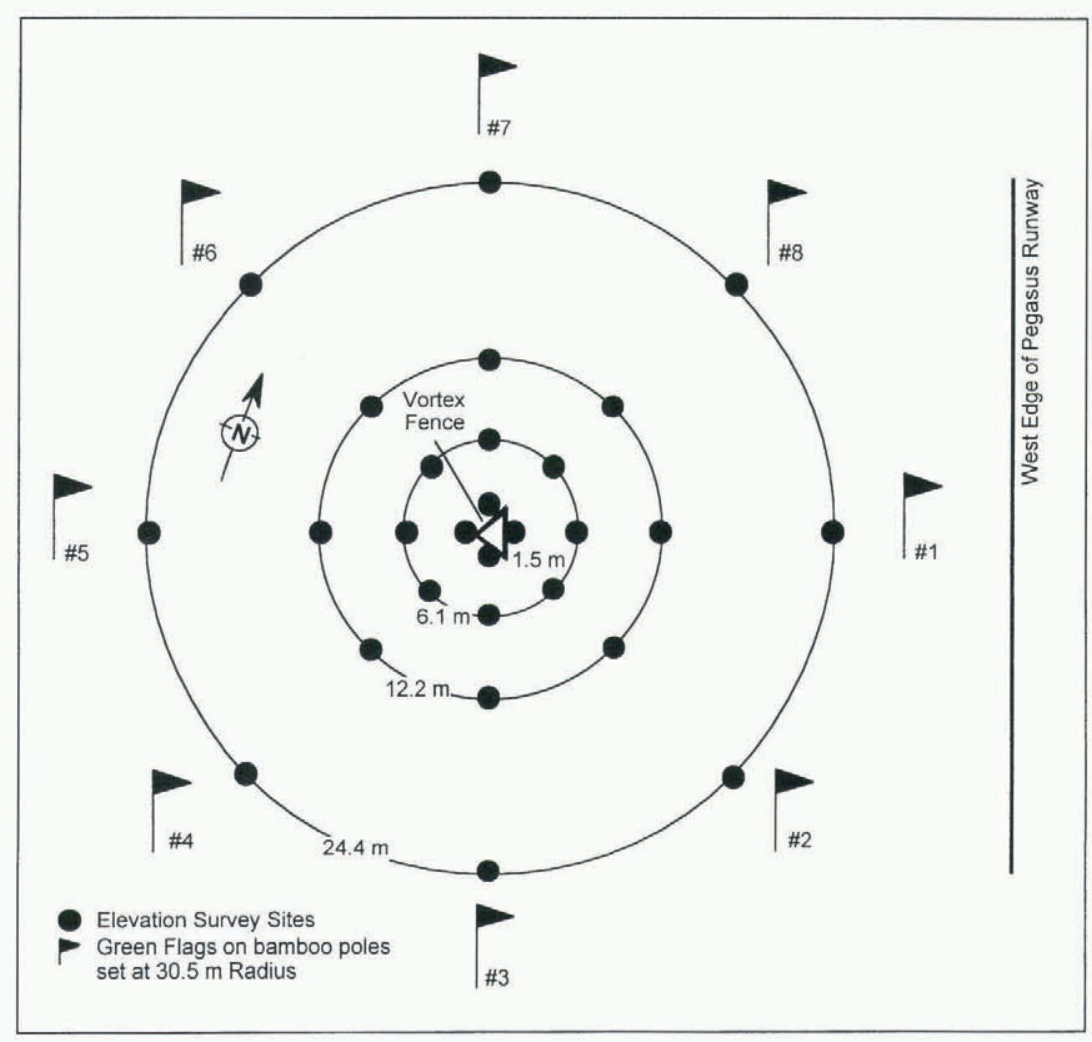

Fig. 5. Survey-target area for the full-scale vortex fence. 


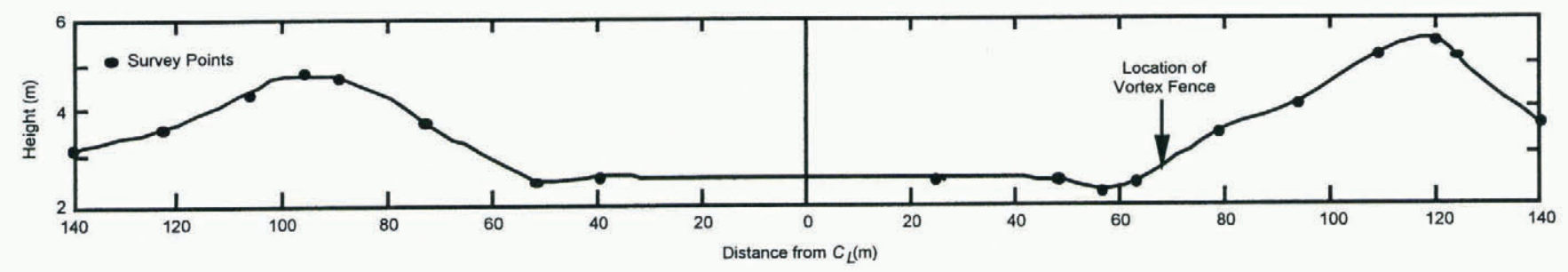

Fig. 6. Berm profile and vortex-fence target area.

was not recorded since time was not available to establish a control survey area nearby. However, measurements from the outboard survey position at station 1 (virtually always upwind relative to the fence) should provide a "normal" reference point for the area. Stations 4 through 7 are the most desirable areas in which to move snow. The snow here was not well-sintered. Within the vortex-target area, the measured surface hardness (i.e. for the upper $10 \mathrm{~cm}$ of snow) ranged from 16 to $18 \mathrm{~kg} \mathrm{f}$ and the densities ranged from $370-$ $475 \mathrm{~kg} \mathrm{~m}^{-3}$. This snow should be removed from the immediate vicinity of the runway to avoid long-term build-up. Although this requires snow to be moved uphill over the west berm, if it could be done, the snow would be transported into the ablation area where it was likely to melt or evaporate.

Erosion results for the full-scale vortex fence are encouraging (Table 1). As expected, accumulation during the austral autumn and into the winter (February through June) occurs at stations 1 and 2. Some accumulation is also

\section{Table 1. Surveyed elevation changes at selected dates in 1995 at each station in the vortex fence target area}

\begin{tabular}{ccccc}
\hline Station & Distance & Elevations bydate & Total \\
fromfence & 7 February & 30 March 15 May & 28 June & change
\end{tabular}

$\begin{array}{llllll}\mathrm{m} & \mathrm{m} & \mathrm{m} & \mathrm{m} & \mathrm{m}\end{array}$

\begin{tabular}{|c|c|c|c|c|c|c|}
\hline 1 & 24.39 & 28.34 & 28.35 & 28.36 & 28.56 & 0.22 \\
\hline 1 & 12.20 & 28.69 & 28.74 & 28.74 & 28.90 & 0.21 \\
\hline 1 & 6.10 & 29.00 & 29.00 & 29.02 & 29.11 & 0.11 \\
\hline 1 & 1.52 & 29.15 & 29.15 & 29.16 & 29.26 & 0.10 \\
\hline 2 & 24.39 & 28.46 & 28.52 & 28.52 & 28.70 & 0.25 \\
\hline 2 & 12.20 & 28.77 & 28.77 & 28.79 & 28.97 & 0.20 \\
\hline 2 & 6.10 & 29.12 & 29.09 & 29.10 & 29.13 & 0.02 \\
\hline 3 & 24.39 & 29.17 & 29.15 & 29.14 & 29.15 & -0.02 \\
\hline 3 & 12.20 & 29.23 & 29.20 & 29.20 & 29.20 & -0.03 \\
\hline 3 & 6.10 & 29.27 & 29.23 & 29.26 & 29.19 & -0.08 \\
\hline 3 & 1.52 & 29.27 & 29.25 & 29.25 & 29.29 & 0.02 \\
\hline 4 & 24.39 & 30.27 & 30.25 & 30.25 & 30.24 & -0.02 \\
\hline 4 & 12.20 & 29.69 & 29.65 & 29.68 & 29.64 & -0.05 \\
\hline 4 & 6.10 & 29.40 & 29.40 & 29.41 & 29.37 & -0.03 \\
\hline 5 & 24.39 & 30.35 & 30.15 & 30.17 & 30.15 & -0.20 \\
\hline 5 & 12.20 & 30.04 & 29.99 & 30.00 & 29.99 & -0.04 \\
\hline 5 & 6.10 & 29.52 & 29.52 & 29.47 & 29.51 & -0.01 \\
\hline 5 & 1.52 & 29.33 & 29.28 & 29.28 & 29.28 & -0.04 \\
\hline 6 & 24.39 & 30.20 & 30.19 & 30.18 & 30.19 & -0.01 \\
\hline 6 & 12.20 & 29.70 & 29.66 & 29.61 & 29.75 & 0.05 \\
\hline 6 & 6.10 & 29.41 & 29.39 & 29.37 & 29.43 & 0.02 \\
\hline 7 & 24.39 & 29.27 & 29.24 & 29.30 & 29.34 & 0.07 \\
\hline 7 & 12.20 & 29.25 & 29.20 & 29.27 & 29.32 & 0.07 \\
\hline 7 & 6.10 & 29.34 & 29.29 & 29.34 & 29.35 & 0.00 \\
\hline 7 & 1.52 & 29.27 & 29.25 & 29.27 & 29.29 & 0.02 \\
\hline 8 & 24.39 & 28.63 & 28.62 & 8.66 & 28.93 & 0.30 \\
\hline 8 & 12.20 & 28.97 & 29.01 & 28.99 & 29.13 & 0.16 \\
\hline 8 & 6.10 & 29.11 & 29.10 & 29.13 & 29.15 & 0.04 \\
\hline
\end{tabular}

seen at station 8, especially at the outermost post and minor accumulation is recorded at stations 6 and 7 . We assume that the snow surface at the outermost survey point at station 1 is unaffected by the fence emplacement, since the vast majority of winds on site come from between $45^{\circ}$ and $180^{\circ}$ (true heading) so it is nearly always upwind of the fence (Fig. 1). Therefore, this survey point should represent a typical depositional pattern. If we also assume that the natural snowdeposition pattern in the entire target area can be represented by the results at outboard survey point at station 1 , then it is possible to calculate the estimated net effect of the vortex fence on snow deposition in the area. This is shown in Table 2, where the total elevation change from Table 1 is modified to subtract the station 1 outboard survey-point elevations through time. This result indicates that the vortex fence had a positive effect (reduced snow accumulation) on the entire $1870 \mathrm{~m}^{2}$ target area except when approaching the

Table 2. Surveyed elevation changes caused by vortex fence referenced to assumed natural deposition (at outermost survey point at Station 1) in the target area

\begin{tabular}{|c|c|c|c|}
\hline Station & $\begin{array}{l}\text { Distance from } \\
\text { fence }\end{array}$ & $\begin{array}{c}\text { Total change } \\
7 \text { Feb.-28 Jun. } 1995\end{array}$ & $\begin{array}{l}\text { Change relative to } \\
\text { natural conditions }\end{array}$ \\
\hline
\end{tabular}

$\mathrm{m}$

$\mathrm{m}$

$\mathrm{m}$

\begin{tabular}{|c|c|c|c|}
\hline 1 & 24.39 & 0.22 & 0.00 \\
\hline 1 & 12.20 & 0.21 & -0.01 \\
\hline 1 & 6.10 & 0.11 & -0.11 \\
\hline 1 & 1.52 & 0.10 & -0.12 \\
\hline 2 & 24.39 & 0.25 & 0.03 \\
\hline 2 & 12.20 & 0.20 & -0.02 \\
\hline 2 & 6.10 & 0.02 & -0.20 \\
\hline 3 & 24.39 & -0.02 & -0.24 \\
\hline 3 & 12.20 & -0.03 & -0.25 \\
\hline 3 & 6.10 & -0.08 & -0.30 \\
\hline 3 & 1.52 & 0.02 & -0.20 \\
\hline 4 & 24.39 & -0.02 & -0.24 \\
\hline 4 & 12.20 & -0.05 & -0.27 \\
\hline 4 & 6.10 & -0.03 & -0.25 \\
\hline 5 & 24.39 & -0.20 & -0.42 \\
\hline 5 & 12.20 & -0.04 & -0.26 \\
\hline 5 & 6.10 & -0.01 & -0.23 \\
\hline 5 & 1.52 & -0.04 & -0.27 \\
\hline 6 & 24.39 & -0.01 & -0.23 \\
\hline 6 & 12.20 & 0.05 & -0.17 \\
\hline 6 & 6.10 & 0.02 & -0.19 \\
\hline 7 & 24.39 & 0.07 & -0.14 \\
\hline 7 & 12.20 & 0.07 & -0.15 \\
\hline 7 & 6.10 & 0.00 & -0.21 \\
\hline 7 & 1.52 & 0.02 & -0.20 \\
\hline 8 & 24.39 & 0.30 & 0.09 \\
\hline 8 & 12.20 & 0.16 & -0.06 \\
\hline 8 & 6.10 & 0.04 & -0.17 \\
\hline
\end{tabular}

\footnotetext{
* Relative to station 1.
} 


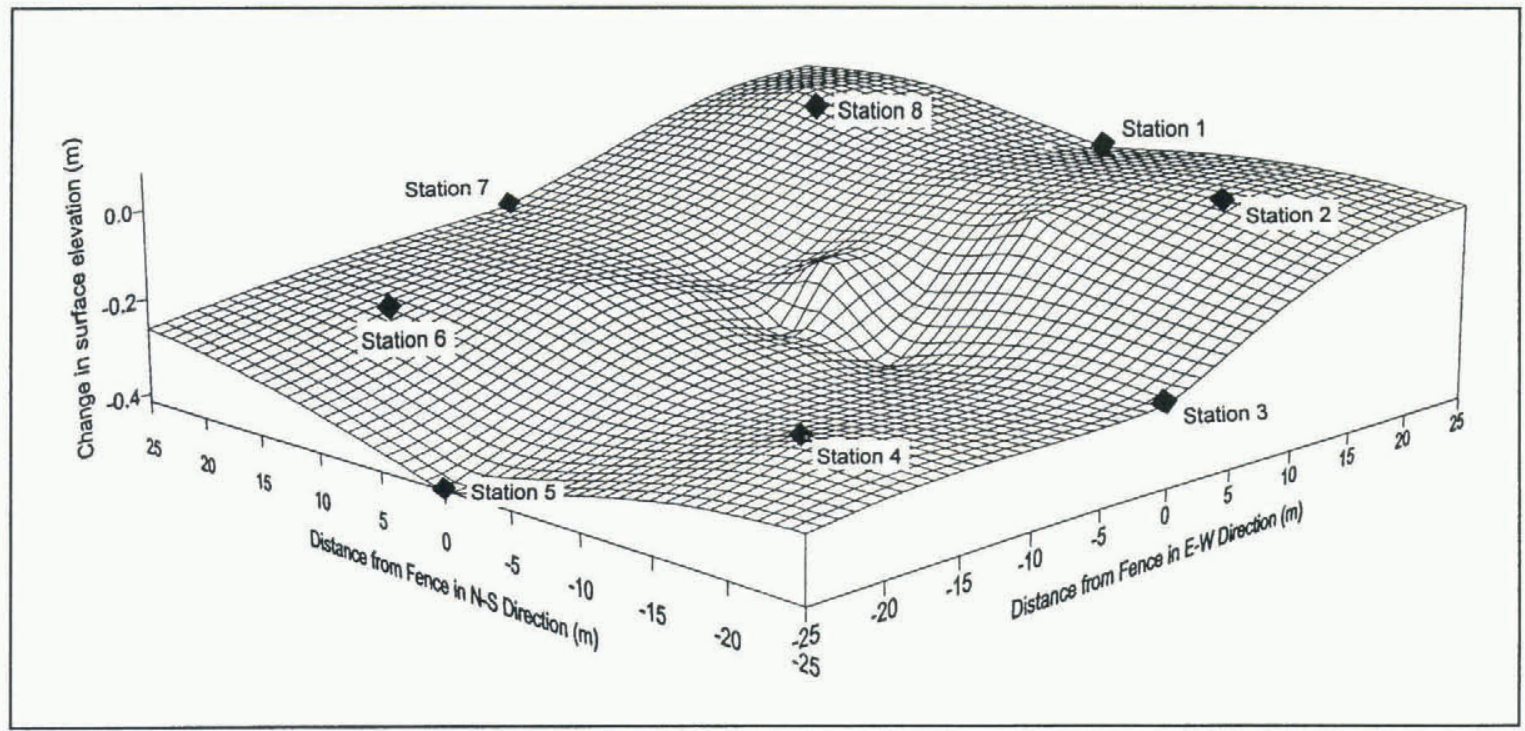

Fig. 7. Perspective map of snow-surface elevation change between 7 February and 28 June 1995, relative to the outboard survey point at station 1 (where no change in natural patterns was assumed). Outermost survey-target positions shown as solid diamonds.

outermost monitoring points at stations 2 and 8 . At these stations, there are very slight increases in snow cover (Table 1; Fig. 7). That these two points show an increase is not surprising since they flank station 1 and are located in the quadrant from which we assume natural snow behavior (i.e. no effect of the vortex fence). All other points within the target area show a significant loss (or reduced accumulation) over what would be the normal depositional pattern.
It is interesting to compare the scour results (Fig. 7) with the wind diagram (derived from an AWS located less than $1 \mathrm{~km}$ away) for the same period (Fig. 8). As anticipated, there is a good correlation between the stations showing the most scour and the most frequent lee directions. More encouraging though is that, over time, scour is effective even in a direction that is leeward to the prevailing wind but windward to the storm wind (station 3). Net erosion also

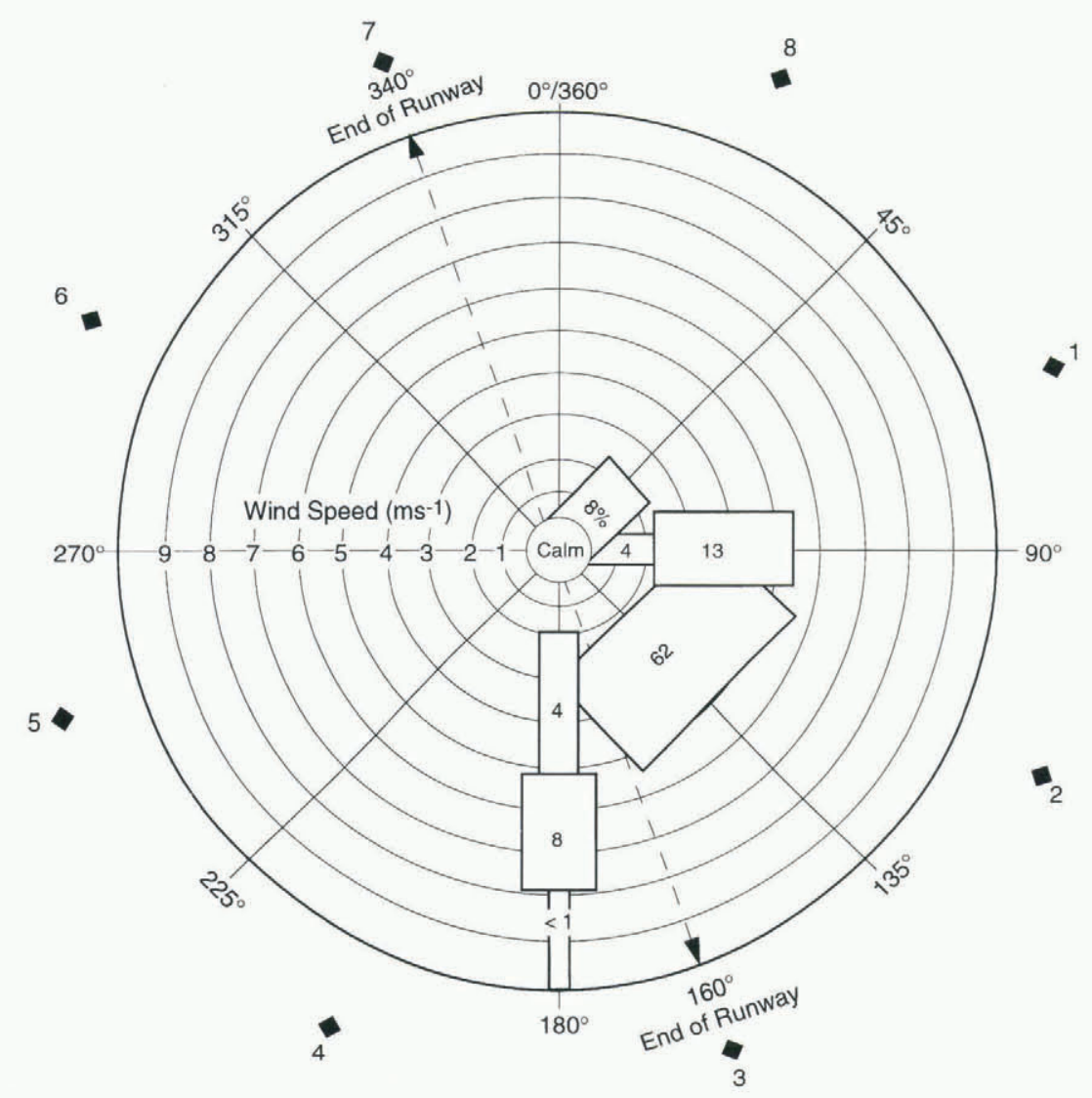

Fig. 8. Wind rose for the "Pegasus South" automated weather station (AWS) using 10-minute readings for the period 8 February to 28 June 1995. The raw data were screened and $17 \%$ of the values were found to be spurious and have been removed for this diagram. Compass orientation of survey-target positions shown as solid diamonds. 
occurred at stations 6 and 7 that are leeward to the storm wind but windward of the prevailing wind.

In our test, the average reduction in surface elevation within the target area was $0.17 \mathrm{~m}$. Thus, within this $1870 \mathrm{~m}^{2}$ area, the fence (with a surface area of only $3.25 \mathrm{~m}^{2}$ ) was able to scour approximately $320 \mathrm{~m}^{3}$ of snow during a 5 month period. This suggests that vortex fences can be a very effective tool for scouring snow. Given the capability to deploy selectively or remove the vortex fence depending on prevailing winds and desired direction of snow scour, a vortex fence could be even more effective.

\section{GONCLUSIONS}

The vortices generated by a vortex fence do not seem to dissipate rapidly, providing effective, sustained erosion. A further advantage of the vortex-fence design is that it lends itself well to a rotating head, which allows the fence to be self-orienting into the wind.

It was shown that a full-scale vortex fence can produce local wind-velocity increases adequate for scouring significant areas of moderately bonded snow surfaces. These tests demonstrated significant snow scour $\left(320 \mathrm{~m}^{3}\right.$ during a 5 month period) over an $1870 \mathrm{~m}^{2}$ area using a relatively small vortex fence (surface area of $3.25 \mathrm{~m}^{2}$ ). In some cases, the vortices were able to move snow upslope.

The vortex fence was placed essentially as a permanent fixture. It is likely that even greater scour could be achieved by judicious deployment and removal of the fence as a function of periods of favorable winds. This would obviously require closer monitoring and the ability to retrieve efficiently and replace the fence depending on existing and forecast winds. This seems like a reasonable trade-off in the light of the potential for greatly increased erosion.

Our full-scale vortex-fence design and installation were based only on rough estimates of the optimum size, height, angle of attack and the extent of propagated longitudinal vortices. Mathematical models of wake turbulence exist and are used routinely in the aircraft industry; these models should be used to determine the most effective arrangement of a vortex fence to achieve snow scour. Further studies should include the determination of the most effective angle of attack and sweep-back angle for the fence, the optimum planform dimensions and height above the snow surface by measuring the velocity distribution leeward of the fence designs.
At the Pegasus site, the annual snow accumulation associated with natural drifting around the construction berms, and mechanically removed runway snow, can be managed with vortex fences. By optimizing the fence spacing based on wake-turbulence models, and employing them only during periods of favorable winds, runway maintenance personnel could efficiently and permanently remove large quantities of unwanted snow with minimal cost, effort and environmental impact.

\section{AGKNOWLEDGEMENTS}

We are very grateful toJ. Sale, who performed all of the surveying for this study, and to many other employees of Antarctic Support Associates (Englewood CO), who assisted in providing site data and in fabricating, installing and monitoring our fences. This work was sponsored by the U.S. National Science Foundation, Office of Polar Programs, Operations Section.

\section{REFERENCES}

Blaisdell, G. L., R. Lang, G. Crist, K. Kurtii, Y. Harbin and D. Flora. 1994. Construction of a glacial ice runway and wheeled flight operations at McMurdo, Antarctica. In Proceedings of the Sixth Symposium on Antarctic Logistics and Operations, Rome, Italy, 29-31 August 1994. Washington, DC, Council of Managers of National Antarctic Programs (COMNAP), 231-242.

Klokov, V. and D. Diemand. 1995. Glaciology of the McMurdo Ice Shelf in the area of air operations. In Elliot, D.H. and G.L. Blaisdell, eds. Contributions to Antarctic research IV. Washington, DC, American Geophysical Union, 175-195. (Antarctic Research Series 67.)

Lang, R. M. and G. L. Blaisdell. 1996. Localized surface-ice weakness on a glacial ice runway. 7. Glaciol., 42(142), 426-439.

McCormick, B.W. 1995. Aerodynamics, aeronautics and flight mechanics. Second edition. New York, John Wiley \& Sons.

McCormick, B. W., J. L. Tangler and H. E. Sherrieb. 1968. The structure of trailing vortices. AIAA J. Aircraft, 5(3), 260-267.

Meroney, B. N. and R. N. Meroney. 1989. Snow control with vortex and blower fences. CRREL Spec. Rep. 89-6, 286-296.

Montagne, J., J. M. McPartland, A. B. Super and H.W. Townes. 1968. Nature and control of snow cornices on the Bridger Range, southwestern Montana. USDA For. Serv. Misc. Rep. 14.

Tabler, R. D. 1991. Snow fence guide. Washington, DC, National Research Council. Strategic Highway Research Program. (Report SHRP-W/ FR-91-106.)

Wang Zhonglong and Chen Yuan. 1980. Research on prevention of snowdrifts by blower fences. f. Glaciol., 26(94), 435-445.

Williams, C. J. 1989. Field observations of wind deflection fins to control snow accumulation on roofs. CRREL Spec. Rep. 89-6, 307-314. 